\title{
The use of amisulpride in the treatment of acute psychosis
}

\author{
Philippe Nuss' \\ Martina Hummer ${ }^{2}$ \\ Cédric Tessier' \\ 'Université Pierre et Marie Curie- \\ Paris6, INSERM U538, Department of \\ Psychiatry, Faculty of Medicine, \\ Pierre et Marie Curie, Paris, France; \\ ${ }^{2}$ Department of Biological Psychiatry, \\ Innsbruck University Hospital, \\ Innsbruck, Austria
}

\begin{abstract}
The management of acute episodes in schizophrenia is frequently initiated in the psychiatric emergency department and requires rapid intervention to relieve distress and psychiatric symptoms. Both non-pharmacological and pharmacological interventions are needed to calm the patient and prevent potential harm to the patient or others. Treatment is a step-by-step process including management of behavioral symptomatology, diagnosis of potential organic causes, and evaluation of potential substance abuse. Better care is delivered if predefined standard operating procedures are adopted systematically. The ultimate goal of treatment is to establish a therapeutic alliance with the patient. Atypical antipsychotics given orally are recommended as a first-line treatment. As the treatment endpoint is calmness rather than sleep, a non-sedative antipsychotic agent is usually preferred. Drug tolerance is a major issue for the patient. Amisulpride is an effective atypical antipsychotic agent in this context. The optimal dose is $800 \mathrm{mg} /$ day, which is effective on positive and negative symptoms and can be given from the first day with a low risk of extrapyramidal symptoms. Since drug-drug interactions are limited, agitation and anxiety may be controlled by short-term adjunctive therapy with benzodiazepines. In conclusion, amisulpride is an appropriate first-line treatment for the management of acute psychosis.
\end{abstract}

Keywords: amisulpride, schizophrenia, acute psychosis, efficacy, safety

\section{Management of acute psychosis}

The management of acute psychosis in schizophrenia is frequently initiated in the psychiatric emergency department. At this stage, patients are often distressed, not necessarily cooperative, out-of-touch, and agitated. Rapid and appropriate treatment is necessary to relieve distress and psychiatric symptoms, to calm the patient, to maintain the patient in a secure treatment environment, and prevent potential harm to the patient or others (Battaglia 2005). Although treatment habits may differ from one hospital to another, expert consensus has been proposed in order to set "best practice" recommendations for acute psychiatric emergences (Allen et al 2001). Acute psychosis is often associated with emergency because of intensity of patient suffering, risk of suicide, and potential harm towards others (Steinert et al 1999). Substance abuse is a frequent comorbid condition. Satisfaction of patients and their families with staff management and medication tolerance is particularly important at this stage of the disease.

\section{Pharmacological management of psychotic symptoms}

Antipsychotic medication is recommended for the treatment of psychotic symptoms during this acute phase. There has been much debate about the relative advantages and disadvantages of oral versus intramuscular route of administration. Although intramuscular formulations have the advantage of ensuring rapid and effective drug delivery, oral medication is generally preferred in the emergency setting if clinically 
feasible; intramuscular administration being usually prescribed only for uncooperative patients (Allen et al 2001). Certain intramuscular formulations are poorly-tolerated, which may compromise long-term adherence to therapy (Currier and Medori 2006).

The attending physician can select from a wide choice of oral antipsychotic medications. Factors influencing the choice of drug include tolerability, rate of onset of efficacy, spectrum of efficacy, and dosage regimen. Side effects, particularly extrapyramidal symptoms, are an important determinant of short- and long-term adherence (Perkins 2002). In this respect, the introduction of atypical antipsychotic drugs which are characterized by a lower propensity for extrapyramidal effects, represent an important advance. A rapid onset of antipsychotic effect is important to control symptoms and to optimize patient retention on treatment. Antipsychotic drugs that can be given immediately at the optimal dose may have advantages in this respect over drugs that need titration. The choice of the right dose to obtain an effective treatment response is critical.

Antipsychotic drugs also differ in their secondary psychotropic effects, some being rather sedative and others having a more activating effect. This heterogeneity of therapeutic dimensional profiles is likely to be due to the relative pharmacological specificity of antipsychotic drugs for different monoamine receptor subtypes (Reynolds 1994; Tamminga 2003). In patients who are highly agitated, a sedative neuroleptic may be considered, although, as described below, use of a non-sedative antipsychotic with an adjunctive benzodiazepine provides a more flexible therapeutic strategy. In contrast, in patients who are unresponsive or uncooperative due to negative symptoms, an antipsychotic with proven efficacy on negative symptoms may be more appropriate. In patients who are uncooperative, drugs requiring a single daily intake may be preferable to those requiring multiple daily administration. Finally, drugs that have important pharmacokinetic or pharmacodynamic interactions with other drugs that may be potentially prescribed in acute psychosis should be used with caution.

It is also important to consider the transition to maintenance therapy. Wherever possible, the antipsychotic used successfully to control symptoms in the acute phase should be continued into the maintenance phase, and switching treatments avoided. It is thus important to take into account the long-term tolerability of antipsychotic medication when choosing a drug to use in the initial phase. For the same reason, combinations of antipsychotic drugs should also be avoided in the acute phase in favor of monotherapy at an adequate dose to achieve successful symptom control.

\section{Pharmacological management of agitation}

For rapid control of agitation, physicians may choose to use a sedative antipsychotic drug from the outset to manage both psychosis and agitation simultaneously. The disadvantage of such a strategy is that the sedative effect can not be removed during the maintenance phase of therapy when it no longer has a therapeutic role to play and remains as a side-effect detrimental to the patient's performance and well-being. Dose reduction to attenuate sedation may be associated with loss of control over psychotic symptoms.

A more flexible alternative is to combine a non-sedative antipsychotic with an anxiolytic drug to control the two symptom clusters independently. In this way, the anxiolytic drug treatment can be stopped when the patient is no longer agitated without compromising control of psychosis. Benzodiazepines are the treatment of choice for the shortterm management of agitation and anxiety in patients with schizophrenia (Wolkowitz and Pickar 1991). A long-acting drug such as diazepam, lorazepam, or alprazolam should be chosen to ensure sustained symptom control (Barbee et al 1992). In particular, well-designed recent studies have demonstrated the utility of lorazepam in association with an antipsychotic in the initial control of agitation in acute psychotic episodes of schizophrenia (eg, Battaglia et al 1997; Foster et al 1997). Intramuscular administration of lorazepam may be useful in the emergency room when patients are highly agitated and uncooperative. Long-term use of benzodiazepines should be avoided to prevent the development of benzodiazepine dependence and emergence of rebound anxiety when treatment is discontinued. An antidepressant with anxiolytic activity may be considered if longer-term treatment of anxiety is needed.

\section{Amisulpride}

The development of atypical antipsychotic drugs represents a significant advance in the treatment of schizophrenia. Some of these drugs may have a more pronounced antipsychotic effect than previously available drugs (Leucht et al 1999; Chakos et al 2001; Davis et al 2003) and all are associated with a lower incidence of extrapyramidal sideeffects for an equivalent level of symptom control compared with conventional drugs (Leucht et al 1999; Geddes et al 2000; Davis et al 2003). Since the occurrence of such side- 
effects is a major determinant of compliance to antipsychotic treatment, the use of the newer atypical drugs allows less treatment discontinuation (Kemmler et al 2005) and thus more consistent long-term control. For this reason, atypical antipsychotics are now recommended as the first-line treatment of choice for patients with schizophrenia in many countries (eg, NICE 2002).

Amisulpride is a $\mathrm{D}_{2} / \mathrm{D}_{3}$ dopamine receptor antagonist with well-characterized atypical antipsychotic properties (McKeage and Plosker 2004). The efficacy of amisulpride in the control of acute psychosis has been demonstrated in twelve randomized clinical trials (Leucht et al 1999, 2002; Geddes et al 2000; Mota et al 2002; Davis et al 2003). These trials have generally demonstrated superior efficacy to that of conventional antipsychotics (Möller et al 1997; Wetzel et al 1998; Puech et al 1998; Carrière et al 2000; Colonna et al 2000) and similar efficacy to two other atypical drugs, risperidone (Peuskens et al 2002; Sechter et al 2002) and olanzapine (Mortimer et al 2004). The clinical effects observed in these different trials are illustrated in Figure 1. The overall clinical response corresponded to an $11 \%(95 \%$ confidence limits: 6\%-16\%) improvement over conventional antipsychotics. Although outside the scope of this review, several clinical trials of six or twelve month duration have demonstrated that the drug is safe and effective for maintenance treatment of psychosis (Naber et al 2003) and for treatment of chronic schizophrenia syndromes (Storosum et al 2002).

Meta-analysis also indicates the relative benefit of atypical antipsychotic drugs over conventional antipsychotics (Davis et al 2003). Amisulpride demonstrates a similar clinical effect to risperidone and olanzapine, a smaller effect relative to clozapine but an apparently improved response to that observed by a number of other drugs (Figure 2). However, these comparisons must be interpreted with caution due to methodological differences between the individual studies.

Amisulpride demonstrated more acceptable and more favorable tolerability, in the treatment of acute psychosis, compared with conventional antipsychotic drugs. The adverse events reported in eleven randomized clinical trials have been pooled in a global analysis (Coulouvrat and Dondey-Nouvel 1999). The most frequent adverse events encountered are listed in Table 1. The incidence of extrapyramidal effects, in general, and of dyskinesia and hypertonia, in particular, was significantly lower in patients treated with amisulpride compared with those receiving conventional antipsychotic drugs.

Indeed, extrapyramidal effects, endocrine effects and weight gain are of particular relevance for the tolerability of antipsychotic drugs. Meta-analysis of the clinical trials comparing amisulpride with conventional antipsychotics

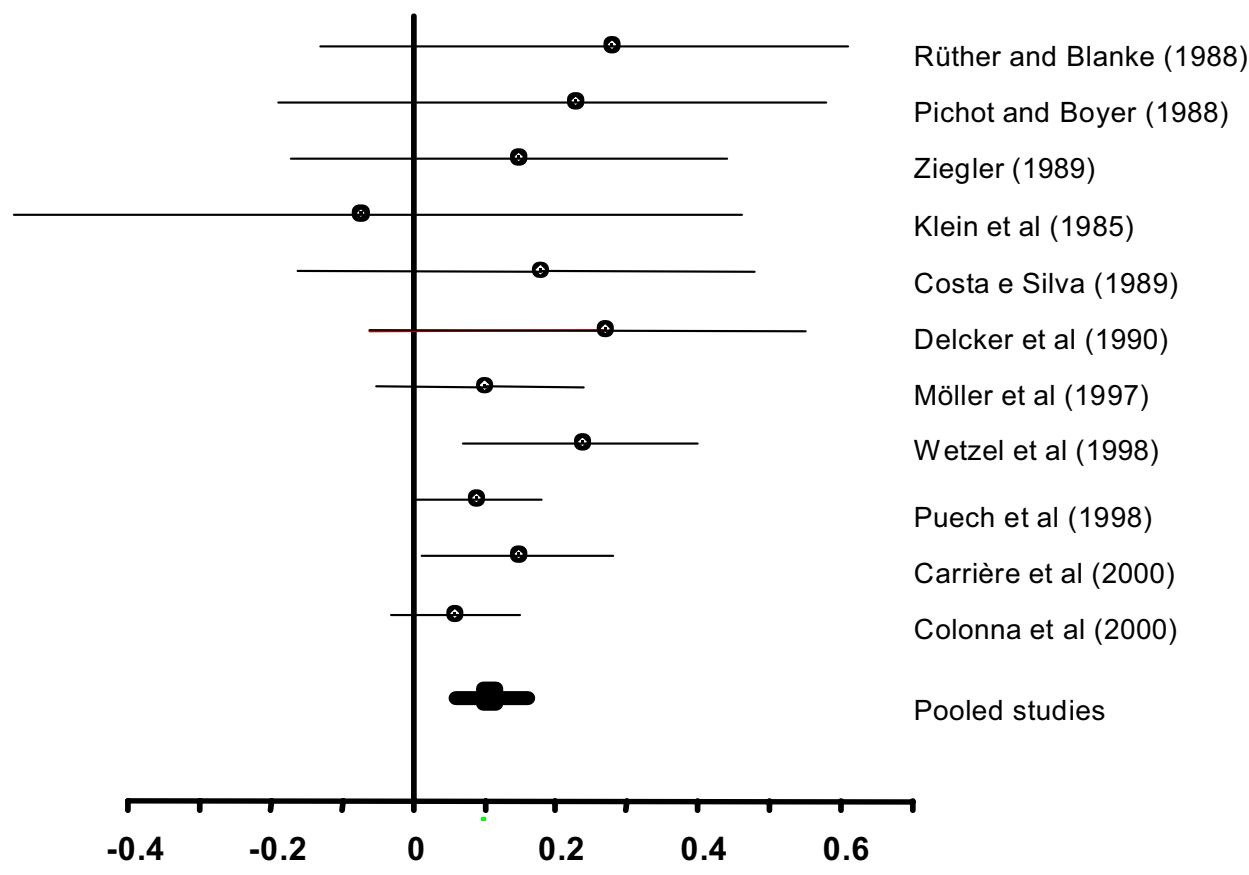

Figure I Meta-analysis of effect sizes in clinical studies of amisulpride compared with first-generation drugs with respect to primary efficacy outcome (change in score on the Brief Psychiatric Rating Scale). 95\% confidence intervals were generated using a randomized effects model. Reprinted with permission from the American Journal of Psychiatry, Copyright (C) 2002, American Psychiatric Association. Leucht S, Pitschel-Walz G, Engel RR, et al. 2002. Amisulpride, an unusual "atypical" antipsychotic: a meta-analysis of randomized controlled trials. Am J Psychiatry, I59:180-90. 
Table I Most frequently-observed treatment-emergent adverse events in clinical trials of amisulpride in the treatment of acute psychosis. Only those events observed in more than $3 \%$ of subjects in any treatment group are listed. The frequency of events indicated in bold was significantly different $(p<0.05)$ in the risperidone or haloperidol group compared with the amisulpride group. Adapted from Coulouvrat and Dondey-Nouvel (1999).

\begin{tabular}{|c|c|c|c|}
\hline Adverse event & $\begin{array}{l}\text { Amisulpride } \\
(n=579)\end{array}$ & $\begin{array}{l}\text { Haloperidol } \\
(n=2 \mid 4)\end{array}$ & $\begin{array}{l}\text { Risperidone } \\
(n=|| 3)\end{array}$ \\
\hline Extrapyramidal disorder & $15 \%$ & $31 \%$ & $12 \%$ \\
\hline Insomnia & $11 \%$ & $12 \%$ & $7 \%$ \\
\hline Hyperkinesia & $9 \%$ & $10 \%$ & $10 \%$ \\
\hline Anxiety & $9 \%$ & $11 \%$ & $6 \%$ \\
\hline Weight gain & $7 \%$ & $2 \%$ & $5 \%$ \\
\hline Agitation & $6 \%$ & $6 \%$ & $4 \%$ \\
\hline Headache & $4 \%$ & $3 \%$ & $10 \%$ \\
\hline Psychosis & $4 \%$ & $2 \%$ & $1 \%$ \\
\hline Constipation & $4 \%$ & $3 \%$ & $1 \%$ \\
\hline Amenorrhoea ( $F$ only) & $4 \%$ & - & $-\%$ \\
\hline Non-puerperal galactorrhoea (F only) & $4 \%$ & $1 \%$ & $4 \%$ \\
\hline Somnolence & $3 \%$ & $5 \%$ & $4 \%$ \\
\hline Dyskinesia & $3 \%$ & $7 \%$ & - \\
\hline Hypertonia & $2 \%$ & $6 \%$ & $5 \%$ \\
\hline Vomiting & $2 \%$ & $2 \%$ & $4 \%$ \\
\hline Rhinitis & $2 \%$ & $1 \%$ & $8 \%$ \\
\hline Fatigue & $2 \%$ & $1 \%$ & $4 \%$ \\
\hline Impotence ( $M$ only) & $1 \%$ & $2 \%$ & $5 \%$ \\
\hline
\end{tabular}

Abbreviations: M, male; F, female.

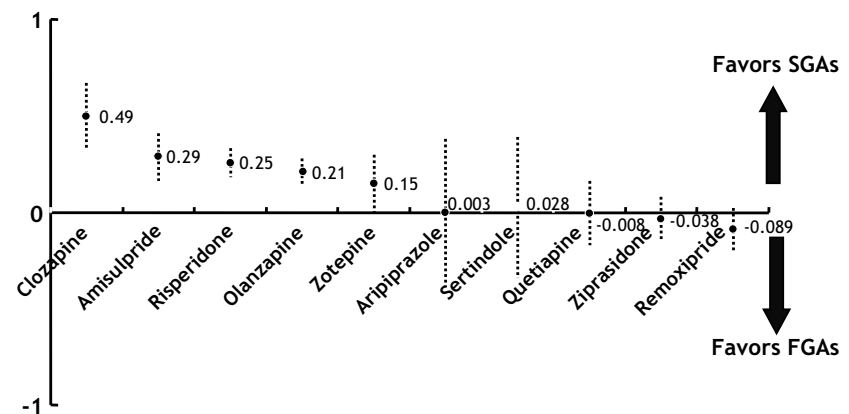

Figure 2 Meta-analysis of effect sizes of second-generation antipsychotic drugs compared to first-generation drugs with respect to primary efficacy outcome. Data for amisulpride are combined from twelve individual studies. Copyright (C) 2005. Reprinted with permission from Davis JM, Chen N. 2005. Old versus new: weighing the evidence between the first- and second-generation antipsychotics. Eur Psychiatry, 20:7-I4.

demonstrates that use of antiparkinsonian medication was $25 \%$ lower ( $95 \%$ confidence intervals: $17 \%-32 \%$ ) in patients receiving amisulpride (Leucht et al 2002) (Figure 3 ) in direct comparison to risperidone or olanzapine (Peuskens et al 1999; Sechter et al 2002; Mortimer et al 2004). The extent of extrapyramidal symptoms and recourse to anticholinergic medication were very similar in head to head trials with these compounds.

With regard to endocrine effects, amisulpride use is associated with elevated serum prolactin in many patients (Coulouvrat and Dondey-Nouvel 1999). Impotence and delayed ejaculation were reported less frequently in

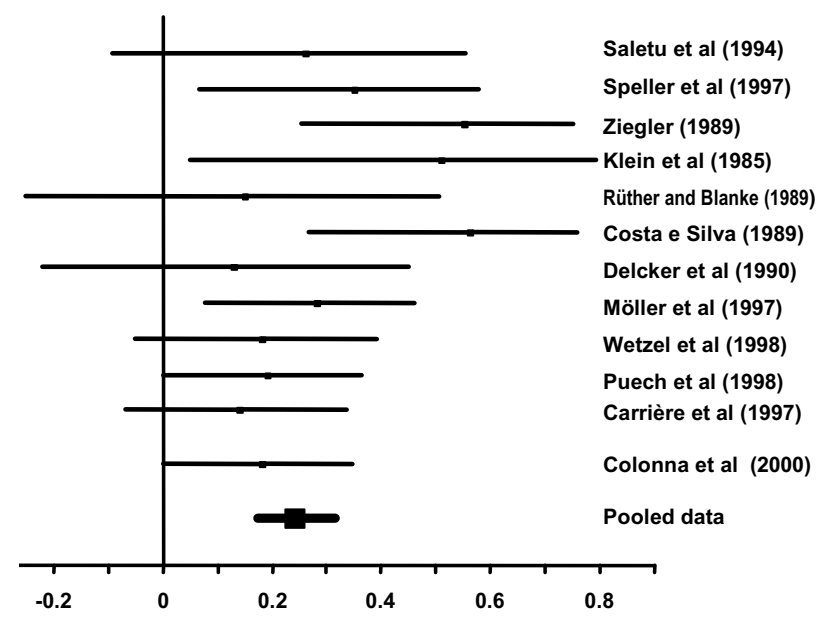

Figure 3 Meta-analysis of effect sizes in clinical studies of amisulpride compared with first-generation drugs with respect to recourse to anticholinergic medication. 95\% confidence intervals were generated using a randomized effects model. Reproduced with permission from the American Journal of Psychiatry, Copyright @ 2002, American Psychiatric Association. Leucht S, Pitschel-Walz G, Engel RR, et al. 2002. Amisulpride, an unusual "atypical" antipsychotic: a metaanalysis of randomized controlled trials. Am J Psychiatry, 159:180-90.

amisulpride-treated patients than in those treated with risperidone. Amenorrhoea was encountered only in the amisulpride group (6.2\%) when compared with olanzapine (Mortimer et al 2004). Weight gain is less frequent and lower in patients receiving amisulpride than in patients treated with risperidone (Sechter et al 2002) or olanzapine (Mortimer et al 2004). 


\section{Choosing the right dose}

The most appropriate dose of amisulpride for the treatment of acute psychosis has been derived from dose-ranging studies, single floating dose studies, and neuroimaging studies. These have consistently supported $800 \mathrm{mg}$ /day as the optimal dose.

\section{Dose-ranging studies}

A single dose-ranging study has been reported for amisulpride in acute psychosis (Puech et al 1998). This evaluated four doses of amisulpride ( $100 \mathrm{mg} /$ day, $400 \mathrm{mg} /$ day, $800 \mathrm{mg} /$ day, and $1200 \mathrm{mg} /$ day) and haloperidol $16 \mathrm{mg} /$ day in five parallel groups of 61-65 patients treated for four weeks. The reference treatment group was the $100 \mathrm{mg} /$ day group, this dose being considered to be sub-therapeutic (pseudo-placebo). Efficacy was assessed as the change from baseline on the Brief Psychiatric Rating Scale (BPRS) (Overall and Gorham 1962). A dose response-curve was obtained (Figure 4) with the largest difference in score from baseline being observed in the $800 \mathrm{mg} /$ day treatment group. The $800 \mathrm{mg} /$ day dose was the only one where there was a significantly larger difference in score $(\mathrm{p}<0.05)$ compared with the $100 \mathrm{mg}$ /day treatment group. A subsequent post hoc analysis of the data from this study revealed that, with the exception of the anergia dimension, responses were highest in all dimensions of the BPRS at the $800 \mathrm{mg}$ dose. The authors concluded that target doses of $700-800 \mathrm{mg}$

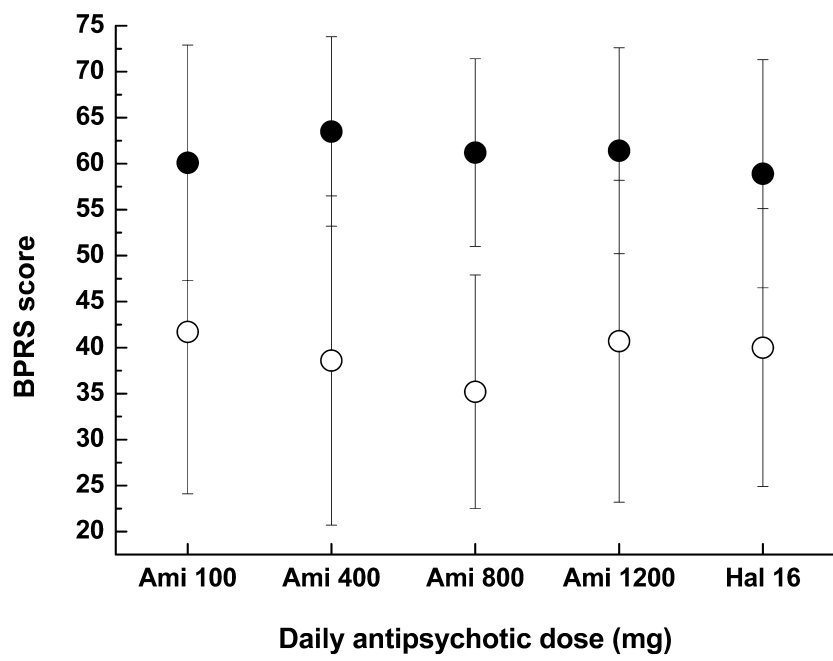

Figure 4 Antipsychotic effect of amisulpride as a function of dose. The data represent the mean (SD) scores on the Brief Psychiatric Rating Scale (BPRS) at inclusion (filled symbols) and after treatment (open symbols) for four weeks with the indicated doses of amisulpride or haloperidol. Data are taken from Puech et al 1998.

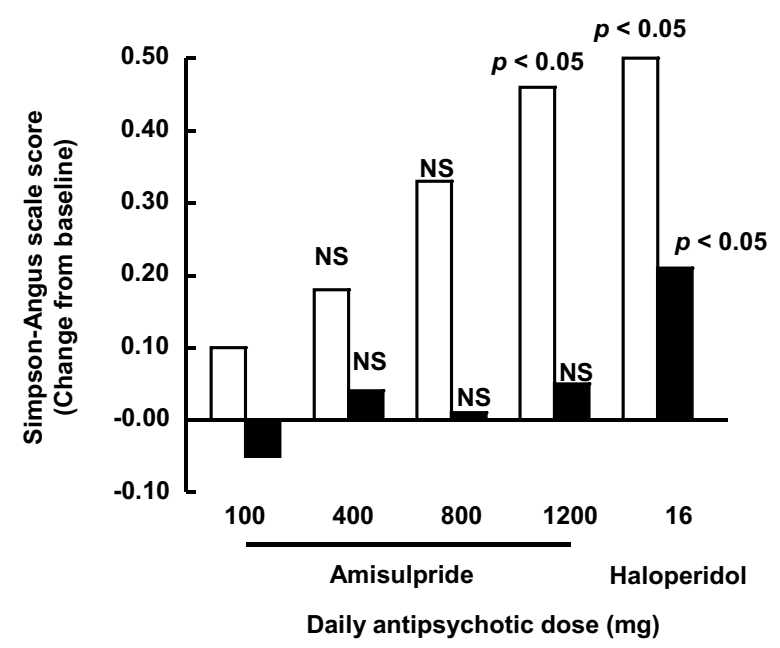

Figure 5 Extrapyramidal impact of amisulpride as a function of dose. The data represent the mean changes from baseline on the Simpson-Angus Scale (SAS) after initiation of treatment with the indicated doses of amisulpride or haloperidol. The open columns represent the maximal change from baseline observed over the course of the study and the filled columns the residual change at study end. Data are taken from Puesch et al 1998.

seemed to be the most appropriate for the treatment of acute psychosis (Müller et al 2002).

The proportion of patients in whom adverse events were reported was similar in all treatment groups. Extrapyramidal effects were assessed with the Simpson-Angus Scale (Simpson and Angus 1970). The maximal change in score from baseline was dose-related, although only the changes observed in the amisulpride $1200 \mathrm{mg} /$ day and haloperidol groups were significantly higher from that in the reference (amisulpride $100 \mathrm{mg} /$ day) group (Figure 5). At study end, changes from baseline in Simpson-Angus Scale scores were rather small, except in the haloperidol treatment group. The results of this study indicate that the dose of $800 \mathrm{mg} /$ day provides the best risk-benefit ratio for the majority of patients in the treatment of acute psychosis.

\section{Single floating dose studies}

Information on the optimal dose of amisulpride can also be found from single floating dose studies. In such studies, the initial dose of amisulpride is fixed and then tailored in individual patients depending upon clinical response. The final dose used corresponds to that considered the most appropriate from the point of view of clinical judgment. In the single study where the starting dose of amisulpride was above $800 \mathrm{mg}$ /day (Wetzel et al 1998), the dose was reduced in $50 \%$ of patients. In all the studies where a starting dose below $800 \mathrm{mg}$ /day was used, the dose was increased over the course of the study. These findings suggest that 
physicians adjusted the dose to converge in the range of 600-800 mg/day. In one study (Möller et al 1997), the dose was initiated at $800 \mathrm{mg} /$ day: here, the dose was adjusted in only $17 \%$ of patients, always in a downward direction.

\section{Neuroimaging studies}

The introduction of high-resolution positron emission tomography (PET) in the 1980s allowed the molecular target of antipsychotic drugs in the brain, the $\mathrm{D}_{2}$ dopamine receptor to be visualized and quantified. A series of studies performed in Sweden led Farde and colleagues (1992) to postulate that a robust antipsychotic response to most antipsychotics (the notable exception being clozapine) was associated with a $70 \%-80 \%$ occupancy of striatal $\mathrm{D}_{2}$ receptors. Lower levels of receptor occupancy were associated with sub-optimal antipsychotic effects and higher levels of occupancy with the manifestation of prominent extrapyramidal effects.

The occupation of striatal $\mathrm{D}_{2}$ dopamine receptors by amisulpride in patients with schizophrenia has since been evaluated using $\left[{ }^{71} \mathrm{Br}\right]$-bromolisuride PET (Martinot et al 1996). The study demonstrated a curvilinear relationship between amisulpride dose and receptor occupancy, with the critical $70 \%-80 \%$ degree of occupancy being obtained over the $630-910 \mathrm{mg}$ dose range (Figure 6). These results also argue in favor of the choice of the $800 \mathrm{mg} /$ day dose as the most appropriate for optimal antipsychotic action.

\section{Dose adjustment}

Neither dose titration nor the use of a loading dose is required for amisulpride and the $800 \mathrm{mg} /$ day dose can be used

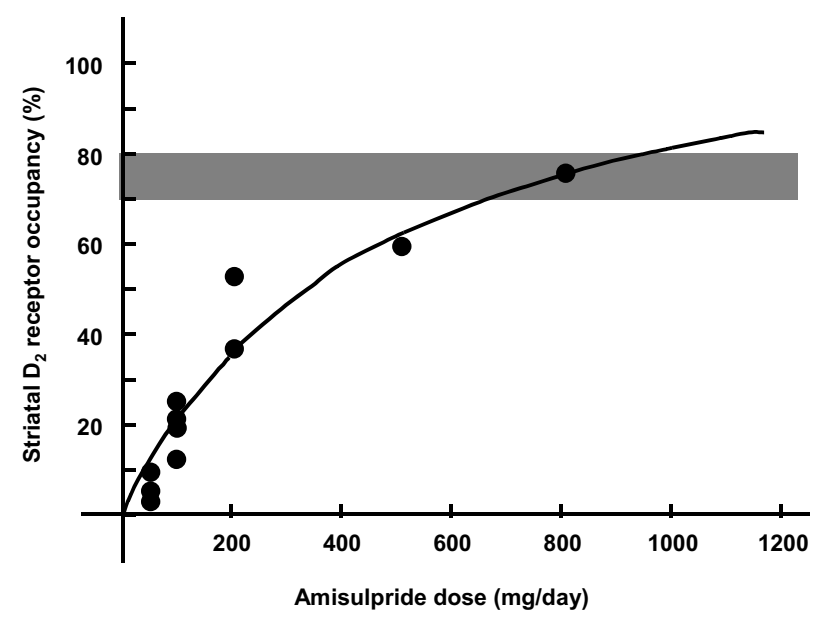

Figure 6 Occupation of striatal $D_{2}$ dopamine receptors measured using positron emission tomography with $\left[{ }^{76} \mathrm{Br}\right]$-bromolisuride as a function of amisulpride dose. The points represent individual patient data and the shaded bar the zone of receptor occupation believed to be optimal for antipsychotic activity. Data are taken from Martinot et al 1996.

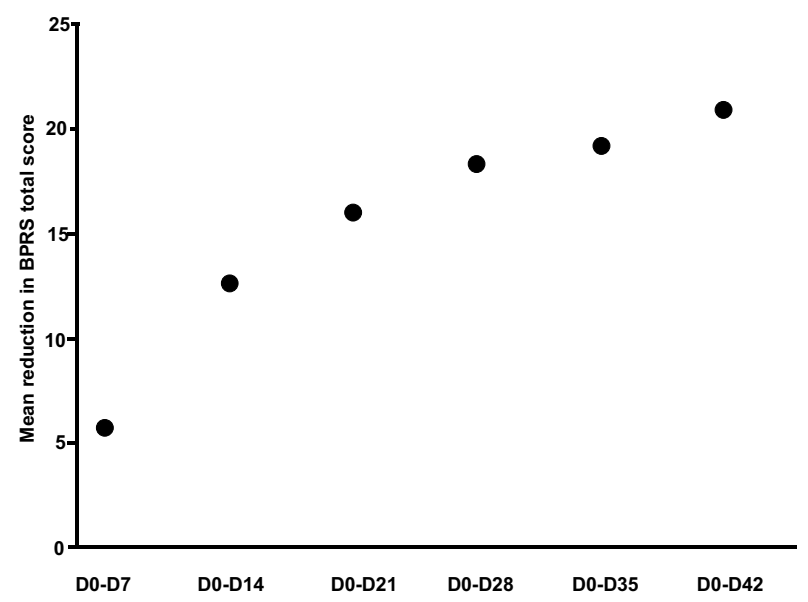

Figure 7 Evolution of Brief Psychiatric Rating Scale (BPRS) total scores after administration of amisulpride $800 \mathrm{mg}$ in patients with acute psychosis. Data are taken from Möller et al 1997.

immediately from the first day. This is due to the relatively simple pharmacokinetics of amisulpride, with rapid absorption and minimal redistribution. This allows steadystate plasma concentrations following repeated dosing to be obtained within $48 \mathrm{~h}$ and $72 \mathrm{~h}$ (Rosenzweig et al 2002).

The ability to use amisulpride at the optimal dose from the first day permits rapid control of psychotic symptoms (Figure 7). This might be an advantage for amisulpride compared with other antipsychotic drugs for which dose titration is needed.

\section{Monitoring and precautions for use}

Although no particular monitoring procedures are required when using amisulpride for the treatment of acute psychosis in most patients, the use of the drug has been associated with prolongation of the QT interval and should thus be used with care in patients with cardiac rhythm disorders. These patients should be monitored regularly by electrocardiogram. Amisulpride is contra-indicated in patients taking drugs affecting cardiac rhythm. Unlike many antipsychotic drugs, amisulpride is not extensively metabolized by hepatic enzymes (Rosenzweig et al 2002) and thus can be used at the standard doses in patients with hepatic impairment. Amisulpride is eliminated in the urine and in patients with impaired renal function, the dose should be reduced in line with creatinine clearance. A pilot study (Riedel et al 2005) provided preliminary evidence that amisulpride $400 \mathrm{mg}$ /day is efficacious for the control of acute psychosis in the elderly. 


\section{Managing agitation}

Although amisulpride is effective in controlling psychotic symptoms, it is not sedative and complementary strategies need to be instituted at the beginning of treatment to control agitation and anxiety if these occur to a significant extent. The most appropriate strategy is use of a benzodiazepine. The benzodiazepine can subsequently be stopped when agitation is adequately controlled so that the patient is not unnecessarily sedated in the long-term. Amisulpride is well suited to such a strategy as it has only a limited capacity for drug interactions due to weak protein binding and lack of interactions with cytochrome P450 drug-metabolizing enzymes (Canal et al 2004). It can thus be used safely in combination with benzodiazepines and other anxiolytics. In particular, a pharmacodynamic interaction study (Perault et al 1998) of amisulpride and lorazepam revealed no interaction between the two drugs. Adjunctive lorazepam use was permitted in the randomized clinical trials of amisulpride in the treatment of acute psychosis and the observed improvements in the 'activation' dimension of the BPRS, which measures agitation and includes tension, hostility, uncooperativeness, and excitement, were comparable with those measured in the other dimensions. Moreover, short-term control of agitation as measured in this way was comparable with that obtained with the sedative atypical, olanzapine (Figure 8). The use of concomitant psychotropic drugs in this study was similar between the amisulpride and olanzapine treatment groups. Benzodiazepines were administered to $47.9 \%$ of amisulpride-treated patients and $50.8 \%$ of olanzapine-

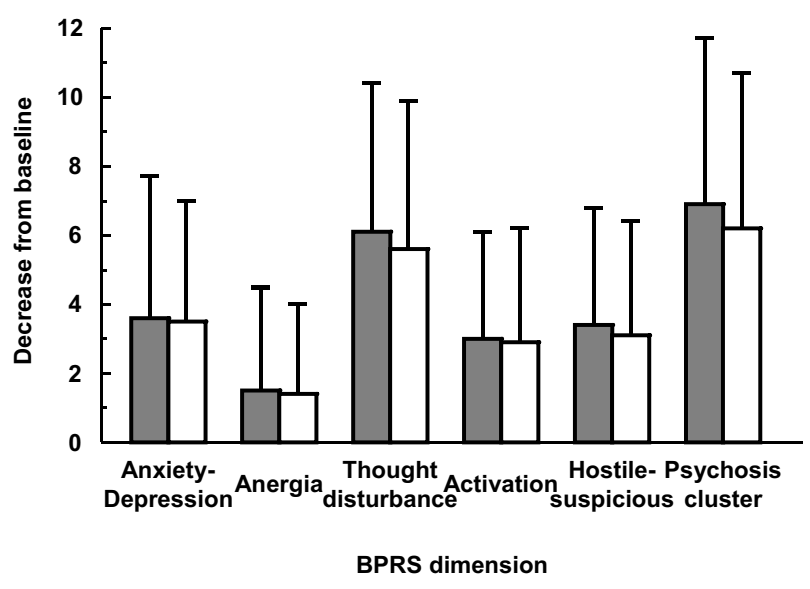

Figure 8 Evolution of Brief Psychiatric Rating Scale (BPRS) dimension scores in a comparative randomised clinical trial of amisulpride versus olanzapine in the treatment of acute psychosis. Data are presented as mean $( \pm S D)$ change from baseline at two months in patients with acute schizophrenia treated with amisulpride (filled columns) or olanzapine (open columns). Adapted from Martin et al 2002
Table 2 Dose evaluation in randomised clinical trials of amisulpride in the acute treatment of schizophrenia using a single floating dose.

\begin{tabular}{lll}
\hline Study & $\begin{array}{l}\text { Starting dose } \\
(\mathbf{m g / d a y})\end{array}$ & $\begin{array}{l}\text { Final dose } \\
(\mathbf{m g / d a y})\end{array}$ \\
\hline Wetzel et al 1998 & 1000 & $907 \pm 177$ \\
Möller et al 1997 & 800 & Maintained in 83\% \\
Carrière et al 2000 & 800 & $600-800$ \\
Sechter et al 2002 & 400 & $683 \pm 204$ \\
Hwang et al 2003 & 400 & $630 \pm 154$ \\
Mortimer et al 2004 & 400 & $504 \pm 150$ \\
\hline
\end{tabular}

treated patients. Use of antidepressants was reported in $<5 \%$ of patients in each group.

In situations where there is no immediate danger, nonpharmacological interventions such as verbal de-escalation may be used to manage the patient's agitation. Every person from the emergency staff, from the reception nurse to medical staff, is involved in this process. Verbal and nonverbal techniques are useful in communicating with the patient. They comprise a calm, warm tone of voice, clear explanation of the treatment process, family reassurance as well as appropriate body position and eye-contact.

In some situations of extreme agitation, where there is a risk of aggression to others, or in cases of disease denial, the use of mechanical restraints such as body belts may be required. This solution should be carefully examined in respect of the patient's civil liberties and staff must be trained to minimize trauma to the patient.

\section{Conclusion}

The management of acute psychosis is based on analysis of symptoms at presentation and requires step by step adjustment. The primary goal is reduction of patient distress. It is often associated with management of agitation and sometimes aggressive behavior. Antipsychotic medication such as amisulpride is an appropriate first-line treatment as it is both effective and well tolerated. The optimal dose of $800 \mathrm{mg} /$ day can be given from the first day, since there is no need for dose titration. In case of agitation and anxiety, short-term adjunctive benzodiazepine therapy is necessary. The use of physical restraint must be a last-resort management option. The ultimate goal of the treatment is to establish a therapeutic alliance with the patient. The transition between the acute and maintenance phases of treatment can be conveniently accomplished, although the $800 \mathrm{mg}$ daily dose, optimal for the treatment of the acute phase, may be reduced afterwards to achieve the lowest adequate maintenance dose. 


\section{References}

Allen MH, Currier GW, Hughes DH, et al; Expert Consensus Panel for Behavioral Emergencies. 2001. The Expert Consensus Guideline Series. Treatment of behavioral emergencies. Postgrad Med, (Spec No): $1-88$

Barbee JG, Mancuso DM, Freed CR, et al. 1992. Alprazolam as a neuroleptic adjunct in the emergency treatment of schizophrenia. Am J Psychiatry, 149:506-10.

Battaglia J. 2005. Pharmacological management of acute agitation. Drugs, 65:1207-22

Battaglia J, Moss S, Rush J, et al. 1997. Haloperidol, lorazepam, or both for psychotic agitation? A multicenter, prospective, double-blind, emergency department study. Am J Emerg Med, 15:335-40.

Canal M, Gilet G, Simpson H. 2004. Lack of drug interaction potential of amisulpride P01-503. Int J Neuropsychopharmacology, 7:S265

Carrière P, Bonhomme D, Lempérière T. 2000. Amisulpride has a superior benefit/risk profile to haloperidol in schizophrenia: results of a multicentre, double-blind study (the Amisulpride Study Group). Eur Psychiatry, 15:321-9.

Chakos M, Lieberman J, Hoffman E, et al. 2001. Effectiveness of secondgeneration antipsychotics in patients with treatment-resistant schizophrenia: a review and meta-analysis of randomized trials. Am J Psychiatry, 158:518-26.

Colonna L, Saleem P, Dondey-Nouvel L, et al; Amisulpride Study Group. 2000. Long-term safety and efficacy of amisulpride in subchronic or chronic schizophrenia, Int Clin Psychopharmacol, 15:13-22.

Costa e Silva JA. 1989. Comparative double-blind study of amisulpride versus haloperidol in the treatment of acute psychotic states. Paris, France, Amisulpride, Expansion Scientifique Française, pp 93-104.

Coulouvrat C, Dondey-Nouvel L. 1999. Safety of amisulpride (Solian): a review of 11 clinical studies. Int Clin Psychopharmacol; 14:209-18

Currier GW, Medori R. 2006. Orally versus intramuscularly administered antipsychotic drugs in psychiatric emergencies. J Psychiatr Pract, 2:30-40.

Davis JM, Chen N, Glick ID. 2003. A meta-analysis of the efficacy of second-generation antipsychotics. Arch Gen Psychiatry, 60:553-64.

Davis JM, Chen N. 2005. Old versus new: weighing the evidence between the first- and second-generation antipsychotics. Eur Psychiatry, 20:714.

Delcker A, Schoon ML, Oczkowski B, et al. 1990. Amisulpride versus haloperidol in treatment of schizophrenic patients - results of a doubleblind study. Pharmacopsychiatry, 23:125-30.

Farde L, Nordstrom AL, Wiesel FA, et al. 1992. Positron emission tomographic analysis of central D1 and D2 dopamine receptor occupancy in patients treated with classical neuroleptics and clozapine: relation to extrapyramidal side effects. Arch Gen Psychiatry, 49:53844.

Foster S, Kessel J, Berman ME, et al. 1997. Efficacy of lorazepam and haloperidol for rapid tranquilization in a psychiatric emergency room setting. Int Clin Psychopharmacol, 12:175-9.

Geddes J, Freemantle N, Harrison P, et al. 2000. Atypical antipsychotics in the treatment of schizophrenia: systematic overview and metaregression analysis. Br Med J, 321:1371-6.

Hwang TJ, Lee SM, Sun HJ, et al. 2003. Amisulpride versus risperidone in the treatment of schizophrenic patients: a double-blind pilot study in Taiwan. J Formos Med Assoc, 102:30-6.

Kemmler G, Hummer M, Widschwendter C, et al. 2005. Dropout rates in placebo-controlled and active-control clinical trials of antipsychotic drugs: a meta-analysis. Arch Gen Psychiatry, 62:1305-12.

Klein HE, Dieterle D, Rüther E, et al. 1985. A double-blind comparison of amisulpride vs haloperidol in acute schizophrenic patients. Pichot P, Berner P, Wolf R, et al (eds). In Psychiatry: The State of the Art, vol 3: Pharmacopsychiatry. Cambridge, Mass, Perseus Books, pp 68791.
Leucht S, Pitschel-Walz G, Abraham D, et al. 1999. Efficacy and extrapyramidal side-effects of the new atypical antipsychotics olanzapine, quetiapine, risperidone, and sertindole compared to conventional antipsychotics and placebo. A meta-analysis of randomized controlled trials, Schizophr Res, 35:51-68.

Leucht S, Pitschel-Walz G, Engel RR, et al. 2002. Amisulpride, an unusual "atypical" antipsychotic: a meta-analysis of randomized controlled trials. Am J Psychiatry, 159:180-90.

Martin S, Loo H, Peuskens J, et al. 2002. A double-blind, randomised comparative trial of amisulpride versus olanzapine in the treatment of schizophrenia: short-term results at two months. Curr Med Res Opin, 18:355-62.

Martinot JL, Paillere-Martinot ML, Poirier MF, et al. 1996. In vivo characteristics of dopamine D2 receptor occupancy by amisulpride in schizophrenia. Psychopharmacology (Berl), 124:154-8.

McKeage K, Plosker GL. 2004. Amisulpride: a review of its use in the management of schizophrenia. CNS Drugs, 18:933-56.

Möller HJ, Boyer P, Fleurot O, et al. 1997. Improvement of acute exacerbations of schizophrenia with amisulpride: a comparison with haloperidol, PROD-ASLP Study Group. Psychopharmacology, 132:396-401.

Müller MJ, Wetzel H, Eich FX, et al; Amisulpride Study Group. 2002. Dose-related effects of amisulpride on five dimensions of psychopathology in patients with acute exacerbation of schizophrenia. $J$ Clin Psychopharmacol, 22:554-60.

Mortimer A, Martin S, Loo H, et al; for the SOLIANOL study group. 2004. A double-blind randomised comparative trial of amisulpride versus olanzapine for six months in the treatment of schizophrenia. Int Clin Psychopharmacol, 19:63-9.

Mota NE, Lima MS, Soares BG. 2002. Amisulpride for schizophrenia. Cochrane Database Syst Rev, 2:CD001357.

Naber D, Arlt J, Lambert M. 2003. Amisulpride: A safe and effective option for the long-term treatment of patients with schizophrenia. Int JPsych Clin Pract, 7:167-75.

NICE. 2002. Schizophrenia - atypical antipsychotics: The clinical effectiveness and cost effectiveness of newer atypical antipsychotic drugs for schizophrenia [online]. Accessed on 20 September 2006. URL: http://www.nice.org.uk/page.aspx?o=32878.

Overall JE, Gorham DR. 1962. The Brief Psychiatric Rating Scale. Psychol Reports, 10:799-812.

Perault MC, Bergougnan L, Paillat A, et al. 1998. Lack of interaction between amisulpride and lorazepam on psychomotor performance and memory in healthy volunteers. Hum Psychopharmacol, 13:493-500.

Perkins DO. 2002. Predictors of noncompliance in patients with schizophrenia. J Clin Psychiatry, 63:1121-8

Peuskens J, Bech P, Möller HJ, et al. 1999. Amisulpride vs. risperidone in the treatment of acute exacerbations of schizophrenia. Amisulpride study group. Psychiatry Res, 88:107-17.

Peuskens J, Moller HJ, Puech A. 2002. Amisulpride improves depressive symptoms in acute exacerbations of schizophrenia: comparison with haloperidol and risperidone. Eur Neuropsychopharmacol, 12:30510.

Pichot P, Boyer P. 1988. Etude multicentrique controlée en double insu, amisulpride (Solian 200) versus halopéridol à forte dose dans les états psychotiques aigus. Annales de Psychiatrie, 3:326-32.

Puech A, Fleurot O, Rein W. 1998. Amisulpride, an atypical antipsychotic, in the treatment of acute episodes of schizophrenia: a dose-ranging study vs. haloperidol. The Amisulpride Study Group, Acta Psychiatr Scand, 98:65-72.

Reynolds GP. 1994. Antipsychotic drug mechanisms and neurotransmitter systems in schizophrenia. Acta Psychiatr Scand Suppl, 380:36-40.

Riedel M, Eich FX, Möller HJ; for the Amielderly group. 2005. A randomised, double-blind clinical trial comparing treatment with amisulpride or risperidone for six weeks in elderly patients with schizophrenia. Eur Neuropsychopharmacology, 15:S515. 
Rosenzweig P, Canal M, Patat A, et al. 2002. A review of the pharmacokinetics, tolerability and pharmacodynamics of amisulpride in healthy volunteers. Hum Psychopharmacol, 17:1-13.

Rüther E, Blanke J. 1988. Therapievergleich von Aminosultoprid (DAN 2163) und Perazin bei schizophrenen Patienten, in Therapie mit Neuroleptika-Perazin. Helmchen H, Hippius H, Tölle R (eds). Stuttgart, Germany, Georg Thieme Verlag, p65-71.

Saletu B, Küfferle B, Gruenberger J, et al. 1994. Clinical, EEG mapping and psychometric studies in negative schizophrenia: comparative trials with amisulpride and fluphenazine. Pharmacopsychiatry, 29:125-35.

Sechter D, Peuskens J, Fleurot O, et al. 2002. Amisulpride vs. risperidone in chronic schizophrenia: results of a 6-month, double-blind study. Neuropsychopharmacology, 27:1071-81.

Simpson GM, Angus JW. 1970. A rating scale for extrapyramidal side effects. Acta Psychiatr Scand Suppl, 212:11-19.

Speller JC, Barnes TRE, Curson DA, et al. 1997. One-year, low-dose neuroleptic study of in-patients with chronic schizophrenia characterised by persistent negative symptoms - amisulpride $\mathrm{v}$ haloperidol. Br J Psychiatry, 171:564-8.
Steinert T, Wiebe C, Gebhardt RP. 1999. Aggressive behavior against self and others among first-admission patients with schizophrenia. Psychiatr Serv, 50:85-90.

Storosum JG, Elferink AJ, van Zwieten BJ, et al. 2002. Amisulpride: is there a treatment for negative symptoms in schizophrenia patients? Schizophr Bull, 28:193-201.

Tamminga CA. 2003. The science of antipsychotics: mechanistic insight. CNS Spectr, 8(11 Suppl 2):5-9.

Wetzel H, Gründer G, Hillert A, et al. 1998. Amisulpride versus flupenthixol in schizophrenia with predominantly positive symptomatology - a double-blind controlled study comparing a selective D2-like antagonist to a mixed D1/D2-like antagonist. Psychopharmacology, 1137:22332 .

Wolkowitz OM, Pickar D. 1991. Benzodiazepines in the treatment of schizophrenia: a review and reappraisal. Am J Psychiatry, 148:71426.

Ziegler B. 1989. Study of the efficacy of a substituted benzamide amisulpride, versus haloperidol, in productive schizophrenia, in Amisulpride. Paris, France, Expansion Scientifique Française, pp 7382. 
